Combining the Particle Size Selector and a Condensation Particle Counter to determine the number size distribution of airborne nanoparticles

Sébastien $\mathrm{Bau}^{\mathrm{a} *}$ and Jonathan Nuvoli ${ }^{\mathrm{a}}$

${ }^{a}$ Department of Pollutant Metrology, Institut National de Recherche et de Sécurité, Vandoeuvre les Nancy, France

*corresponding author: sebastien.bau@inrs.fr / +33 383509890 


\title{
Combining the Particle Size Selector and a Condensation Particle Counter to determine the number size distribution of airborne nanoparticles
}

\begin{abstract}
This study fits in the general framework of developing methods for the measurement of the number size distribution of airborne submicrometer particles suited for field measurements. An approach based on the combination of a Particle Size Selector (PSS) and a portable Condensation Particle Counter (CPC) is proposed in this work. The methodology relies on the successive measurement of the number concentration under 6 operational configurations $(\mathrm{n}=0,1,2,6,12$ and 18 diffusion screens). A first part of this work consisted of determining particle penetration through different sets of diffusion grids, both experimentally and theoretically. On that basis, a specific data processing was developed, assuming that aerosol size distribution follows a monomodal lognormal law. In the second part of this study, the combined PSS-CPC approach was applied to a series of test aerosols produced in the laboratory, covering a range of modal diameters from 9 to $270 \mathrm{~nm}$. Compared to reference SMPS data, the output number size distributions calculated from the PSS-CPC approach were found to be within $\pm 11 \%$ in terms of modal diameter, which is considered satisfactory.
\end{abstract}

Keywords: nanoaerosol; size distribution; PSS-CPC combination

\section{Introduction}

Particle size is among the key determinants of their deposition within the respiratory apparatus (Broday \& Rosenzweig, 2011; ICRP, 1994), as well as their behavior in workplace atmospheres (Hinds, 1999). Therefore, determining the size distribution of airborne particles is crucial when a characterization of occupational exposure is sought (Maynard \& Aitken, 2007). Such measurement often involves expensive techniques; most of them are not suitable for workplace measurements due to their low timeresolution, lack of field-portability, and require high levels of expertise (Leskinen et al., 2012; Stabile et al., 2014). 
The use of Condensation Particle Counters has been recently suggested in a series of measurement strategies associated with nanomaterial-related operations, as stated by OECD (2015). In addition, some models of CPC have been developed for being used in the field, accounting for their high portability: battery-operated, lightweight, internal data logging. For these reasons, CPC have been widely used in workplace measurement campaigns according to a recent review (Viitanen et al., 2017).

When they are standalone operated, CPC do not allow particle size distribution to be determined. However, when coupled to a selection device, specific fractions of an aerosol can be measured, which is part of the number size distribution of airborne particles.

Following this rationale, Feldpausch et al. (2006) proposed to use three configurations (3, 8 and 17 diffusion screens) of the Particle Size Selector (PSS, TSI 376060), each of them being placed upstream of a CPC (TSI models 3010 and 3760A). SEM pictures of the diffusion grids are provided in Figure 1. The parallel measurement of the number concentrations corresponding to different fractions of the aerosol was used to determine the number size distribution thanks to an inversion procedure described in Fiebig et al. (2005). The inverted size distributions were compared to reference SMPS data for a 3 test aerosols generated in the laboratory, with a narrow range of count median diameter from 23 to $30 \mathrm{~nm}$.

Although relying on similar philosophy, the approach implemented in this work involves the sequential measurement of the number concentration by means of a single CPC placed downstream of different sets of diffusion grids. Using a single CPC for all measurements avoids consider the possible differences in terms of size range covered, counting efficiencies and modes (single count vs photometric), as well as the variability between different models, which can reach up to 25\% (Bau et al., 2017). To ensure 
reliable number size distribution derived from the successive measurements, the aerosol is supposed to be stable during the whole sequence, however.

Because this work fits in the framework of developing methods suited for the measurement in occupational environments, portable device were selected: Counter: CPC TSI model 3007; Selector: Particle Size Selector, PSS TSI model 376060. This choice was driven by (1) the operation in single count mode only over the whole range of number concentration (up to $10^{5} \# / \mathrm{cm}^{3}$ ), (2) the size range covered from 10 to 1000 $\mathrm{nm},(3)$ the affordable cost $(<10 \mathrm{k} €),(4)$ the robustness of diffusion screens made of stainless steel, and finally (5) the field-portability (battery-operated, lightweight) of the setup. In addition, this combination does not rely on a high expertise level of the user.

In this work, an approach based on the combination of a PSS and a CPC was developed. This methodology enables the calculation of the number size distribution of airborne submicrometer particles. More precisely, the sequence consists of measuring 6 number concentration downstream of the PSS equipped with different sets of diffusion screens, successively. A first step of this study focused on the measurement of particle penetration through diffusion grids to validate the corresponding mathematical description. Second, a simple optimization algorithm was implemented and tested on theoretical aerosols to establish the limits of the approach. Last, experiments were conducted in the laboratory where test aerosols were produced in a wide range of modal diameters from 9 to $270 \mathrm{~nm}$. The output number size distributions stemming from combined PSS-CPC were compared to reference SMPS data. 


\section{Materials and Methods}

\subsection{Theoretical penetration of particle penetration through diffusion screens}

Based on the work published by Cheng and Yeh (1980), the penetration $P$ of a particle through a set of $n$ diffusion grids is given by:

$$
P=\exp \left(\frac{-\left(n\left(4 \alpha\left(E_{D}+E_{R}+E_{I}+E_{D R}\right) t\right)\right.}{\pi(1-\alpha) d_{f}}\right)
$$

With $\alpha$ and $t$ the solid fraction (compacity) and the thickness of the diffusion grid, respectively, and $d_{f}$ the fiber diameter. In this equation, $E_{D}, E_{R}, E_{I}$ and $E_{D R}$ represent particle collection efficiency by diffusion, interception, impaction and combined diffusion/interception, respectively. The latter combined mechanism corresponds to enhanced deposition due to interception of diffusing particles. Because the penetration of uncharged and charged particles was found to be equivalent (Alonso et al., 1997; Ichitsubo et al., 1996), particle collection due to electrostatic effects were neglected. In addition, particle deposition by gravitational sedimentation being very small for submicrometer particles, this deposition mechanism was also ignored. Equations allowing calculate the collection efficiencies due to the different mechanisms, $E_{D}, E_{R}, E_{I}$ and $E_{D R}$, are provided in Table 1, as well as the parameters inherent to the diffusion grids used.

From calculations, the 5 following configurations were retained: $1,2,6,12$ and 18 diffusion grids. For nanoparticle present as agglomerates, which is supposed for most cases, such configurations correspond to "equivalent" cutoff diameters of $\approx 20,40$, 100, 230 and $500 \mathrm{~nm}$, respectively. 


\subsection{Experimental measurement of particle penetration through different sets of diffusion grids}

A first step of this work consisted of experimentally measuring the penetration of particles through different sets of diffusion grids. The latter data were subsequently compared to the theoretical penetration calculated by means of the equations mentioned in Table 1.

The experimental setup used in this first step is depicted in Figure 2. It is based on the successive measurement of the number concentration of monodisperse particles with and without diffusion grids. In particular, polydisperse airborne particles produced either with the CAIMAN test bench (Jacoby et al., 2011) or with a nebulizer (AGK2000, Palas) are selected according to their electrical mobility by means of an electrostatic classifier (TSI 3082) in a Differential Mobility Analyzer (DMA, TSI 3081). This selection through the DMA results in an aerosol considered to be monodisperse, containing multiple charge particles at very low proportions, typically below $15 \%$ according to Bau et al. $(2009,2012)$ The monodisperse aerosols are then directed to the Condensation Particle Counter (TSI 3007) where their number concentration is measured after passing through the Particle Size Selector (PSS TSI 376060) containing no diffusion grid $\left(C_{N_{\text {no grid }}}\right), n$ diffusion grids $\left(C_{N_{n \text { grids }}}\right)$, and again no diffusion grid $\left(C^{\prime}{ }_{N_{\text {no grid }}}\right)$, successively. Therefore, the experimental penetration $P_{\exp }$ of particles of size $d_{m}$ through $n$ diffusion grids is calculated according to:

$$
P_{\text {exp }}\left(d_{m}\right)=\frac{C_{N_{\text {ngrids }}}}{\frac{C_{N_{\text {no grid }}+C^{\prime} N_{\text {no grid }}}}{2}}
$$

In our experimental procedure, each concentration was averaged over a period of time of minimum 5 minutes. Furthermore, aerosol stability was ensured by comparing the concentrations without diffusion grid: 


$$
C_{N_{\text {no grid }}}^{\prime}=C_{N_{\text {no grid }}} \pm 5 \%
$$

In case the latter equation was not satisfied, corresponding experimental data were disregarded.

It is worth noting that particle penetration through the (empty) diffusion grid holder was also determined to ensure that its contribution to the overall penetration be neglected (penetration $P^{P S S} \approx 1$, losses $\approx 0$ ). In this case, the experimental setup was slightly modified, and following sequence was adopted: no PSS - PSS with no diffusion grid - no PSS. The penetration is then calculated by:

$$
P_{\text {exp }}^{P S S}\left(d_{m}\right)=\frac{C_{N_{\text {no grid }}}}{\frac{C_{N_{\text {no } P S S}+C^{\prime} N_{\text {no } P S S}}}{2}}
$$

The test aerosols produced for the purpose of penetration measurement are described in Table 2. For each substance, the range of particle diameters covered is also specified. Agglomerates were produced in an overall range of electrical mobility diameters from 13 to $500 \mathrm{~nm}$, with overlapping ranges between the 5 different substances, while spherical particles of DEHS covered a range from 50 to $1000 \mathrm{~nm}$.

\subsection{Determination of the number size distribution of airborne particles from sequential concentration measurements}

\subsubsection{Mathematical description}

Based on the penetration curves, the number concentration $C_{N}(n)$ measured downstream of the Particle Size Selector equipped with $n$ diffusion grids corresponds to:

$$
C_{N}(n)=\sum_{d_{p}} C_{N}\left(d_{p}\right) P\left(d_{p}, n\right)
$$

in which $C_{N}\left(d_{p}\right)$ is the number size distribution of the particles. 
Therefore, the sequential measurement of particle number concentrations downstream of the PSS containing different sets of diffusion grids allows estimate the number size distribution of the aerosol. The more configurations of $n$, the more accurate the number size distribution estimated.

Mathematically, the problem consists of finding out the number size distribution $C_{N}\left(d_{p}\right)$ that best satisfies the following equations system:

$$
\left\{\begin{array}{c}
C_{N}\left(n_{1}\right)=\sum_{d_{p}} C_{N}\left(d_{p}\right) P\left(d_{p}, n_{1}\right) \\
C_{N}\left(n_{2}\right)=\sum_{d_{p}} C_{N}\left(d_{p}\right) P\left(d_{p}, n_{2}\right) \\
\vdots \\
C_{N}\left(n_{k}\right)=\sum_{d_{p}} C_{N}\left(d_{p}\right) P\left(d_{p}, n_{k}\right)
\end{array}\right.
$$

\subsubsection{Approach}

To avoid implementing complex inversion procedures (eg Dubtsov et al. (2017); Fiebig, et al. (2005); Onischuk et al. (2018)), we assumed the number size distribution sought to be ideally lognormal and monomodal, henceforth described by only two parameters: the modal diameter $d_{50}$ and the geometric standard deviation GSD. The total number concentration $C_{N}(n=0)$ is considered as a constant from the measurement of the CPC with the PSS containing no diffusion grid. Therefore, solving the equations system 5 aims at determining the best couple $\left(d_{50}, G S D\right)$. This optimization was performed by using Excel Solver to minimize criterion $\Delta$ as defined by:

$$
\Delta=\sum_{i}\left[C_{N}\left(n_{i}\right)-C_{N}^{*}\left(n_{i}\right)\right]^{2}
$$

where $C_{N}\left(n_{i}\right)$ is the actual number concentration downstream of the PSS with $n_{i}$ diffusion grids $\left(n_{i}>0\right)$, and $C_{N}^{*}\left(n_{i}\right)$ the concentration calculated from corresponding equation 4 assuming $C_{N}\left(d_{p}\right)$, described by a couple $\left(d_{50}, G S D\right)$. 


\subsubsection{Limits of the approach}

The performances of the methodology in the determination of the best lognormal number size distribution were evaluated on theoretical aerosols. In practice, this consisted of:

- $\quad$ setting a theoretical distribution $C_{N}^{\text {theo }}\left(\mathrm{d}_{\mathrm{p}}\right)$, based on a couple $\left(d_{50}^{\text {theo }}, G S D^{\text {theo }}\right)$,

- calculating the corresponding number concentrations $C_{N}^{\text {theo }}\left(n_{i}\right)$,

- using this simulated dataset as "actual" number concentrations in equation 5 ,

- performing the optimization procedure, yielding an optimized couple $\left(d_{50}, G S D\right)$.

Simulating couples $\left(d_{50}^{\text {theo }}, G S D^{\text {theo }}\right)$ in a wide range therefore leads to the theoretical establishment of bias maps. The latter highlight the range of aerosols for which the optimization allows the input distribution to be recovered. For instance, the "$30 \%$ bias" curve, corresponding to all situations for which $\frac{d_{50}}{d_{50}^{\text {theo }}}=0.7$, can be displayed. Accordingly, $x \%$ bias curves can be represented to mark out different regions in the bias map.

In addition, the size of particles detected by the CPC used (TSI model 3007) ranges from $10 \mathrm{~nm}$ to $1 \mu \mathrm{m}$. Therefore, boundaries were defined, beyond which more than $5 \%$ of the aerosol is expected to not be detected. These boundaries were also represented in the bias map to help the user check whether optimization results are in the area where all conditions are fulfilled.

\subsection{Application of the methodology to a series of test aerosols}

The abovementioned procedure was applied to a set of polydisperse test aerosols generated in the laboratory. Experiments depicted in figure 3 consisted of measuring 
sequentially the number concentration of airborne particles downstream of the PSS containing $n$ diffusion grids ( $n=0,1,2,6,12$ and 18). In parallel, the reference number size distribution was measured by the SMPS (composed of: neutralizer TSI 3088, classifier TSI 3082, DMA TSI 3081, CPC TSI 3787, $Q_{\text {aero }}=0.6 \mathrm{~L} \cdot \mathrm{min}^{-1}, Q_{\text {sheath }}=$ 3 to $6 \mathrm{~L} \cdot \mathrm{min}^{-1}$, depending on the size range targeted).

Because of the use of six configurations (no grid +5 sets of diffusion grids), each experimental condition was maintained for a minimum of 30 minutes ( 3 minutes average for each concentration +1 minute stabilization).

The test aerosols produced in the laboratory are described in Table 3. All test aerosols are monomodal, and quite well described by a lognormal size distribution. Among them, 50 cases correspond to agglomerates presenting modal diameters ranging from 9 to $270 \mathrm{~nm}(\mathrm{GSD} \approx 1.5)$. The other 27 cases represent spherical particles with modal diameters ranging from 36 to $108 \mathrm{~nm}$ with GSD between 1.7 and 3.3.

The SMPS data were fitted by lognormal distribution; the corresponding modal diameter and GSD, noted $d_{50}^{r e f}$ and $G S D^{r e f}$, were used as reference. The adjusted number size distribution from PSS-CPC measurements, noted $d_{50}^{\text {exp }}$ and $G S D^{\text {exp }}$, were then compared to reference values stemming from SMPS. For each experiment, the following ratios were calculated:

$$
\begin{aligned}
& R_{\text {mode }}=\frac{d_{50}^{e x p}}{d_{50}^{r e f}} \\
& R_{G S D}=\frac{G S D^{e x p}}{G S D^{r e f}}
\end{aligned}
$$

To help the user conclude about the proportion of the smallest particles, the fractions of particles below 50 and $100 \mathrm{~nm}$, noted $f_{50}$ and $f_{100}$, respectively, were 
calculated for both the SMPS and PSS-CPC measurements. Considering experiments carried out on agglomerated particles, SMPS-based fractions were $0 \leq f_{50}^{r e f} \leq 1$ and $0 \leq f_{100}^{r e f} \leq 1$. The ranges are narrower for spherical particles with $0.1 \leq f_{50}^{\text {ref }} \leq 0.6$ and $0.4 \leq f_{100}^{r e f} \leq 0.9$

\section{Results and Discussion}

\subsection{Particle penetration through diffusion grids}

As stated earlier, a preliminary point consisted of measuring the penetration of particles through the PSS grid holder without diffusion screen (equation 3). Experimental results (data not shown) obtained for particles in a range from 13 to $1000 \mathrm{~nm}$ (DEHS, Carbon and Silver test aerosols described in Table 2) highlight a penetration of $94 \%$ for $13 \mathrm{~nm}$ particles. As soon as particles are in the range $20-1000 \mathrm{~nm}$, penetration was found to be $>97 \%$. Thus, the contribution of the empty PSS to the overall penetration can be neglected (losses $\leq 3 \%$ for $d_{p} \geq 20 \mathrm{~nm}$ ).

Experimental measurements of particle penetration (equation 2) through different sets of diffusion grids are gathered in Figure 4 for $n=1,2,6,12$ and 18 grids. Along with experimental data, the theoretical penetration for both spheres and agglomerates is also provided.

To fit the experimental data, parameter $B$ involved in the diffusional collection of particles (Table 1) was adjusted by minimizing the following parameter for each set of $n$ diffusion grids:

$$
\Delta^{\prime}=\sum_{d_{m}}\left[P_{\exp }\left(d_{m}\right)-P\left(d_{m}\right)\right]^{2}
$$

This yielded 5 optimal values of $B$ (one for each configuration), which were then averaged to lead to (1) $B=1.57 \pm 0.06$ for spherical particles, which is in line with 
Cheng and Yeh (1980) who recommend $B \in[1,5 ; 2]$ for real filter, and (2) $B=2.32 \pm$ 0.06 for agglomerates, in agreement with Feldpausch, et al. (2006) who reported $B$ in the range $2.43-2.95$.

For agglomerated particles, constants $C_{1}$ and $C_{2}$ were also optimized according to the same procedure based on the minimization of the residues between experimental and theoretical penetration (equation 7), leading to $C_{1}=1.55 \pm 0.59$ and $C_{2}=$

$0.95 \pm 0.07$. This is in agreement with the coefficients provided by Chen et al. (2013) who reported $C_{1}=1.047$ and $C_{2}=1.088$ for Ag aggregates with a fractal dimension of 2.25. Indeed, according to Charvet et al. (2014), airborne particles produced within the CAIMAN facility present a fractal dimension of $\sim 2.2$.

Based on these optimized parameters, the agreement between theoretical and experimental data is satisfying. Therefore, the use of equations provided in Table 1 allows particle penetration to be well described.

\subsection{Bias maps}

From equations gathered in Table 1 and optimized parameters from monodisperse experiments, theoretical aerosols were used to determine the range of "validity" of the approach proposed, according to the procedure described above. The bias maps displaying the relative discrepancy between input (theoretical) and output (PSS-CPC combination) modal diameter are proposed for agglomerates and spheres in figure 5. As stated in section 2.3.3., situations in which more than 5\% of the aerosol is expected to not be detected are displayed as a grey-shaded zone in Figure 5.

Therefore, the user can easily check whether the output from the combined PSSCPC approach is in the domain of validity (white area), and have an order of magnitude 
of the error associated with the modal diameter stemming from the inversion computation.

From figure 5, it can be stated that the calculation procedure is applicable for aerosols with modal diameter between 20 and $250 \mathrm{~nm}$ and GSD below 3, where the output aerosol properties (mode, GSD) are found within an acceptable error of $\pm 30 \%$ compared to the input parameters. This step allowed the calculation procedure to be optimized and its range of validity to be evaluated theoretically.

\subsection{Results of the application of the methodology to various test aerosols}

When applied to a given test aerosol produced in the laboratory (Figure 3, Table 3), the methodology leads to the determination of 6 number concentrations provided by the CPC downstream of the PSS equipped successively with $0,1,2,6,12$ and 18 diffusion screens.

Examples of results stemming from the optimization procedure are compared to SMPS reference measurements and SMPS-based fits in Figure 6 for 3 test aerosols, covering modal diameters from 36 to $110 \mathrm{~nm}$. Here, the PSS-CPC-based and SMPSbased modal diameters agree within $\pm 5 \%$, while GSD agree within $\pm 15 \%$.

To account for all test aerosols produced in the framework of this study, the ratios of the PSS-CPC-output parameters relative to SMPS-based reference parameters (modal diameter and GSD) were determined and are presented as boxplots in Figure 7 for the case of agglomerates and spheres, respectively. It is worth mentioning that, out of the 50 agglomerate test aerosols, 5 experiments have been disregarded, due to a modal diameter out of range $(<20 \mathrm{~nm})$ or the non-convergence of the optimization procedure, as well as 2 cases out of the 27 sphere test aerosols.

Median modal diameter ratios are found to be 1.00 and 0.89 for agglomerates and spheres, respectively. In addition, the median GSD ratios are 0.94 and 0.87 . This 
highlights the possibility for the PSS-CPC approach to accurately estimate the number size distribution of airborne particles. In addition, no significant effect of aerosol modal diameter has been observed. We therefore conclude that the approach proposed based on the successive measurement of number concentrations is reliable for the determination of particle number size distribution.

As stated earlier, the calculation also provides specific fractions of the output aerosol. The fractions of particles below $50 \mathrm{~nm}$ (squares) and $100 \mathrm{~nm}$ (circles) calculated from PSS-CPC approach are compared to SMPS-based fractions in Figure 8 for agglomerates and spheres, respectively. From a general point of view, the fractions are in agreement between reference and PSS-CPC approach: $60 \%$ of the cases for agglomerates within $\pm 30 \%$, and $70 \%$ for the case of spheres. Therefore, providing information regarding typical fractions of particles as a complement to the number size distribution seems faithful, especially for non-specialists, e.g. people not accustomed to read number size distributions of airborne particles.

\section{Conclusions}

In the framework of developing methods allowing the measurement of particle number size distribution, an approach based on the combination of a selector (PSS) and a portable particle counter (CPC) was proposed. This methodology is suited for workplace measurement. It relies on the successive measurement of the number concentration under 6 operational configurations, associated with a specific data processing based on the assumption that the aerosol is distributed according to a monomodal lognormal law.

Because the computational procedure involves the penetration of particles through diffusion screens, a first part of this study focused on the experimental determination of the penetrations as well as the optimization of the associated equations. 
This step was carried out in the laboratory by means of the generation of monodisperse aerosols $(13-1000 \mathrm{~nm})$, and leaded to the validation of the mathematical description of the PSS under the configurations retained.

Theoretical cases were then used to determine the accuracy of the calculation protocol. The bias maps obtained show that the calculated distribution recovers within \pm $30 \%$ the input one for a wide range of aerosols with modal diameters from roughly 20 to $270 \mathrm{~nm}$ and GSD below 3 .

The PSS-CPC approach was then applied to a series of test aerosols produced in the laboratory, covering a range of modal diameters from 9 to $270 \mathrm{~nm}$. The number size distributions calculated from the combined PSS-CPC data were compared to reference SMPS data. Altogether, the median ratios between the modal diameters measured by the reference and those stemming from the PSS-CPC approach were found to be within \pm $11 \%$. This demonstrates that the PSS-CPC approach allows estimate the number size distribution of airborne particles.

The limits of the approach have also been determined. A strong hypothesis relies on the assumption that the aerosol is monomodal and follows a lognormal number size distribution. The case of multi-modal aerosols, which requires more parameters to be optimized in the calculation (two modal diameters, two GSD and the proportion of each population), shall be investigated. This is of particular interest when several aerosol sources are identified.

The second strong assumption is relative to the stability of the aerosol over a period of time of $\sim 20$ minutes ( 6 configurations, 3 min each) This constitutes the major limit of the methodology for application to field cases. In practice, this period can be reduced to $\sim 10$ minutes during which the aerosol to be measured is supposed to be stable. A "lighter" approach based on less configurations (eg. 0, 6 and 18 grids only) 
could be of interest for aerosol screening in case of doubts regarding the stability of the aerosol.

Changing the number of configurations or the shape of the distribution (eg. bimodal distribution) requires to review the inversion procedure. Indeed, in this work, the single case of monomodal lognormal size distribution has been investigated and validated with theoretical cases. In addition, in case the operating flow rate (CPC used) is modified, experimental measurement of the penetration of particles is also needed to validate the theoretical description of the penetration curves established in monodisperse mode.

Considering that the PSS-CPC approach is now validated under laboratory conditions, the application of this methodology to field measurements constitutes a major perspective of this study. 


\section{References}

Alonso, M., Kousaka, Y., Hashimoto, T., \& Hashimoto, N. (1997). Penetration of Nanometer-Sized Aerosol Particles Through Wire Screen and Laminar Flow Tube. Aerosol Science and Technology, 27, 471-480.

Bau, S., Toussaint, A., Payet, R., \& Witschger, O. (2017). Performance study of various Condensation Particle Counters (CPCs): development of a methodology based on steady-state airborne DEHS particles and application to a series of handheld and stationary CPCs. Journal of Physics: Conference Series, 838, 012002.

Bau, S., Witschger, O., Gensdarmes, F., \& Thomas, D. (2009). Experimental study of the response functions of direct-reading instruments measuring surface-area concentration of airborne nanostructured particles. Journal of Physics: Conference Series, 170, 012006.

Bau, S., Witschger, O., Gensdarmes, F., \& Thomas, D. (2012). Evaluating three directreading instruments based on diffusion charging to measure surface area concentrations in polydisperse nanoaerosols in molecular and transition regimes. J. Nanopart. Res., 14, 1217-1233.

Broday, D.M., \& Rosenzweig, R. (2011). Deposition of fractal-like soot aggregates in the human respiratory tract. Journal of Aerosol Science, 42, 372-286.

Brown, R.C. (1993). Air Filtration : An Integrated Approach to the Theory and Applications of Fibrous Filters. Pergamon Press.

Charvet, A., Bau, S., Paez-Coy, N.E., Bémer, D., \& Thomas, D. (2014). Characterizing the effective density and primary particle diameter of airborne nanoparticles produced by spark discharge using mobility and mass measurements (tandem DMA/APM). J. Nanopart. Res, 16, 2418.

Chen, S.-C., Wang, J., Fissan, H., \& Pui, D.Y.H. (2013). Exposure assessment of nanosized engineered agglomerates and aggregates using Nuclepore filter. $J$. Nanopart. Res., 15, 1995.

Cheng, Y.S., \& Yeh, H.C. (1980). Theory of a screen-type diffusion battery. Journal of Aerosol Science, 11, 313-320.

Dubtsov, S., Ovchinnikova, T., Valiulin, S., Chen, X., Manninen, H.E., Aalto, P.P., \& Petäjä, T. (2017). Laboratory verification of Aerosol Diffusion Spectrometer and the application to ambient measurements of new particle formation. Journal of Aerosol Science, 105, 10-23.

Feldpausch, P., Fiebig, M., Fritzsche, L., \& Petzold, A. (2006). Measurement of ultrafine aerosol size distribution by a combination of diffusion screen 
seperators and condensation particle counters. Journal of Aerosol Science, 37, 577-597.

Fiebig, M., Stein, C., Schröder, F., Feldpausch, P., \& Petzold, A. (2005). Inversion of data containing information on the aerosol particle size distribution using multiple instruments. Journal of Aerosol Science, 36, 1353-1372.

Hinds, W.C. (1999). Aerosol Technol. : Properties, Behavior, and Measurement of Airborne Particles. John Wiley \& Sons.

Ichitsubo, H., Hashimoto, T., Alonso, M., \& Kousaka, Y. (1996). Penetration of Ultrafine Particles and Ion Clusters Through Wire Screens. Aerosol Science and Technology, 24, 119-127.

ICRP. (1994). Human Respiratory Tract Model for Radiological Protection (Vol. 24).

Jacoby, J., Bau, S., \& Witschger, O. (2011). CAIMAN: a versatile facility to produce aerosols of nanoparticles. Journal of Physics: Conference Series, 304, 012014.

Kim, S.C., Wang, J., Emery, M.S., Shin, W.G., Mulholland, G.W., \& Pui, D.Y.H. (2009). Structural Property Effect of Nanoparticle Agglomerates on Particle Penetration through Fibrous Filter. Aerosol Science and Technology, 43, 344355.

Leskinen, J., Joutsensaari, J., Lyyränen, J., Koivisto, J., Ruusunen, J., Järvelä, M., Tuomi, T., Hämeri, K., Auvinen, A., \& Jokiniemi, J. (2012). Comparison of nanoparticle measurement instruments for occupational health applications. $J$. Nanopart. Res., 14, 718-733.

Maynard, D., \& Aitken, R.J. (2007). Assessing exposure to a airborne nanomaterials : Current abilities and future requirements. Nanotoxicology, 1, 26-41.

OECD. (2015). Harmonized tiered approach to measure and assess the potential exposure to airborne emissions of engineered nano-objects and their agglomerates and aggregates at workplaces. ENV/JM/MONO(2015)19, 55, 51.

Onischuk, A.A., Baklanov, A.M., Valiulin, S.V., Moiseenko, P.P., \& Mitrochenko, V.G. (2018). Aerosol diffusion battery: The retrieval of particle size distribution with the help of analytical formulas. Aerosol Science and Technology, 52, 165181.

Stabile, L., Cauda, E., Marini, S., \& Buonanno, G. (2014). Metrological assessment of a portable analyzer for monitoring the particle size distribution of ultrafine particles. Ann. Occup. Hyg., 58, 860-876. 
Stechkina, I.B., \& Fuchs, N.A. (1966). Studies on Fibrous Aerosol Filters-I.

Calculation of Diffusional Deposition of Aerosols in Fibrous Filters. Annals of Occupational Hygiene, 9, 59-64.

Viitanen, A.-K., Uuksulainen, S., Koivisto, A.J., Hämeri, K., \& Kauppinen, T. (2017). Workplace Measurements of Ultrafine Particles - A Literature Review. Annals of Work Exposures and Health, 61, 749-758.

Yeh, H.C., and Liu, B.Y.H. (1974). Aerosol Filtration by Fibrous Filters. Journal of Aerosol Science, 5, 191-217. 


\section{Figures}

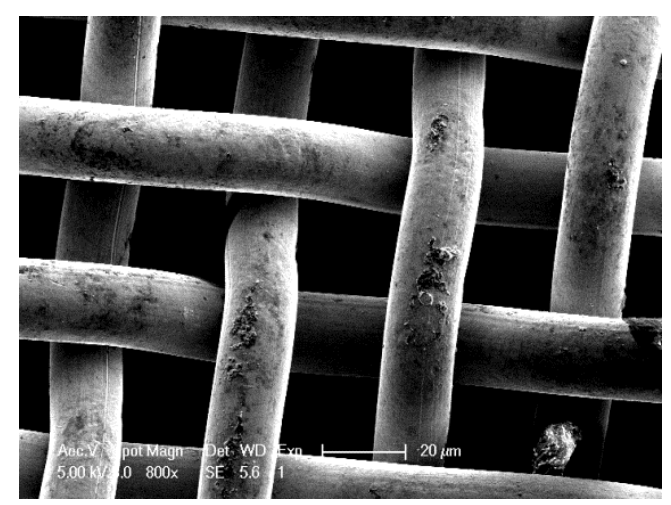

Figure 1. SEM pictures of the diffusion screens used in the Particle Size Selector involved in this study. 


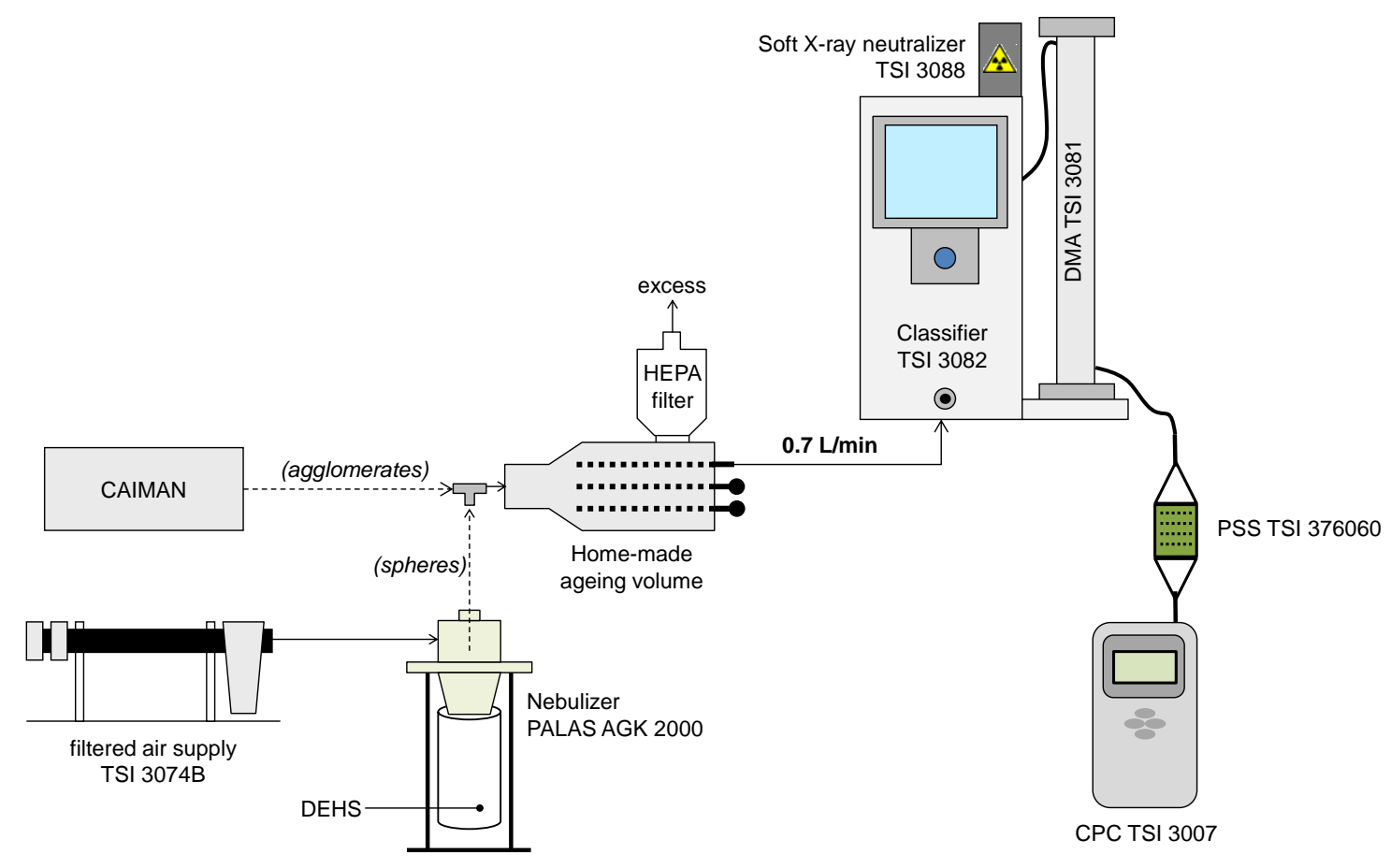

Figure 2. Experimental setup for the measurement of particle penetration through the Particle Size Selector (monodisperse aerosols). 


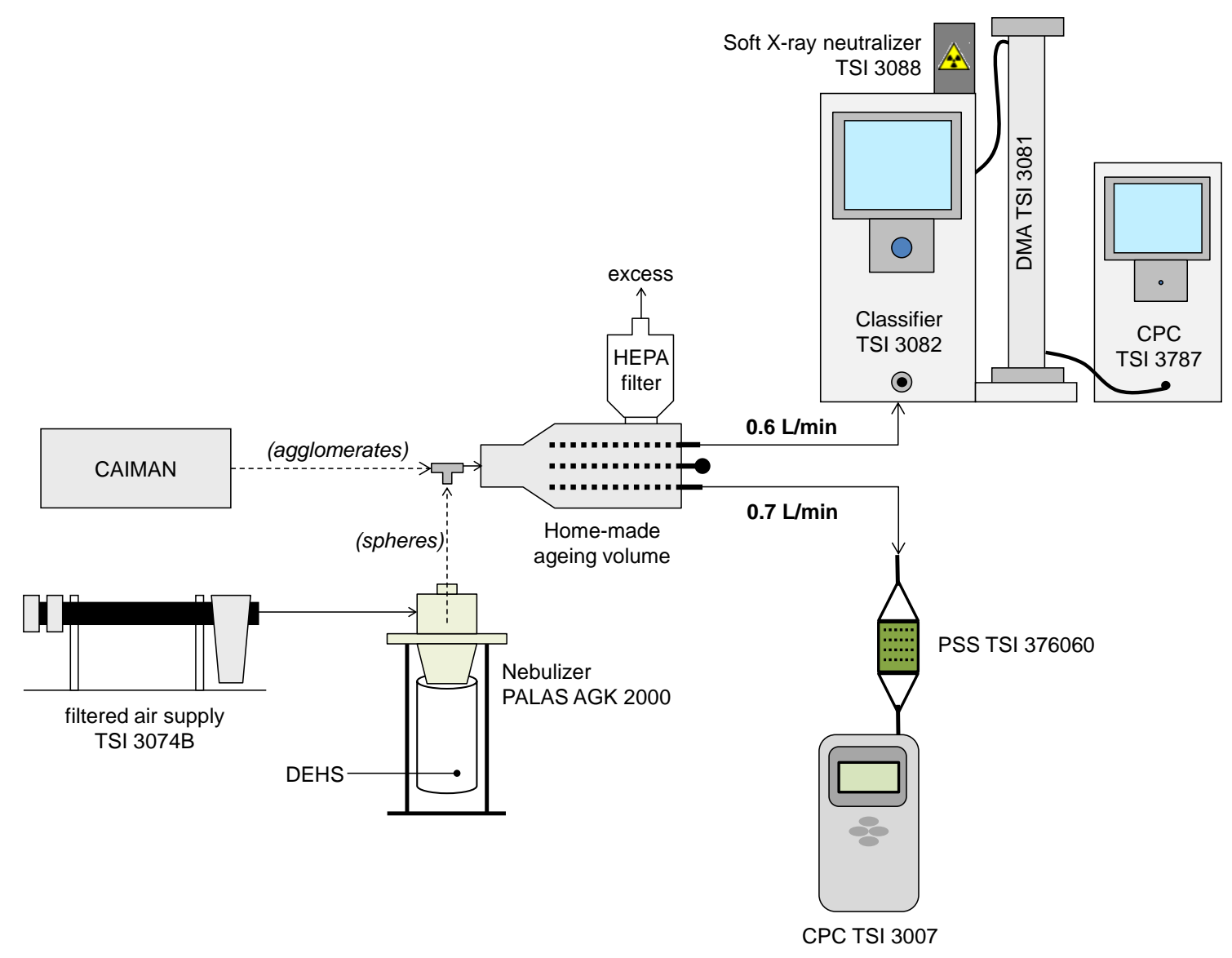

Figure 3. Experimental setup for the comparison between PSS-CPC size distribution and reference measurement (SMPS). 

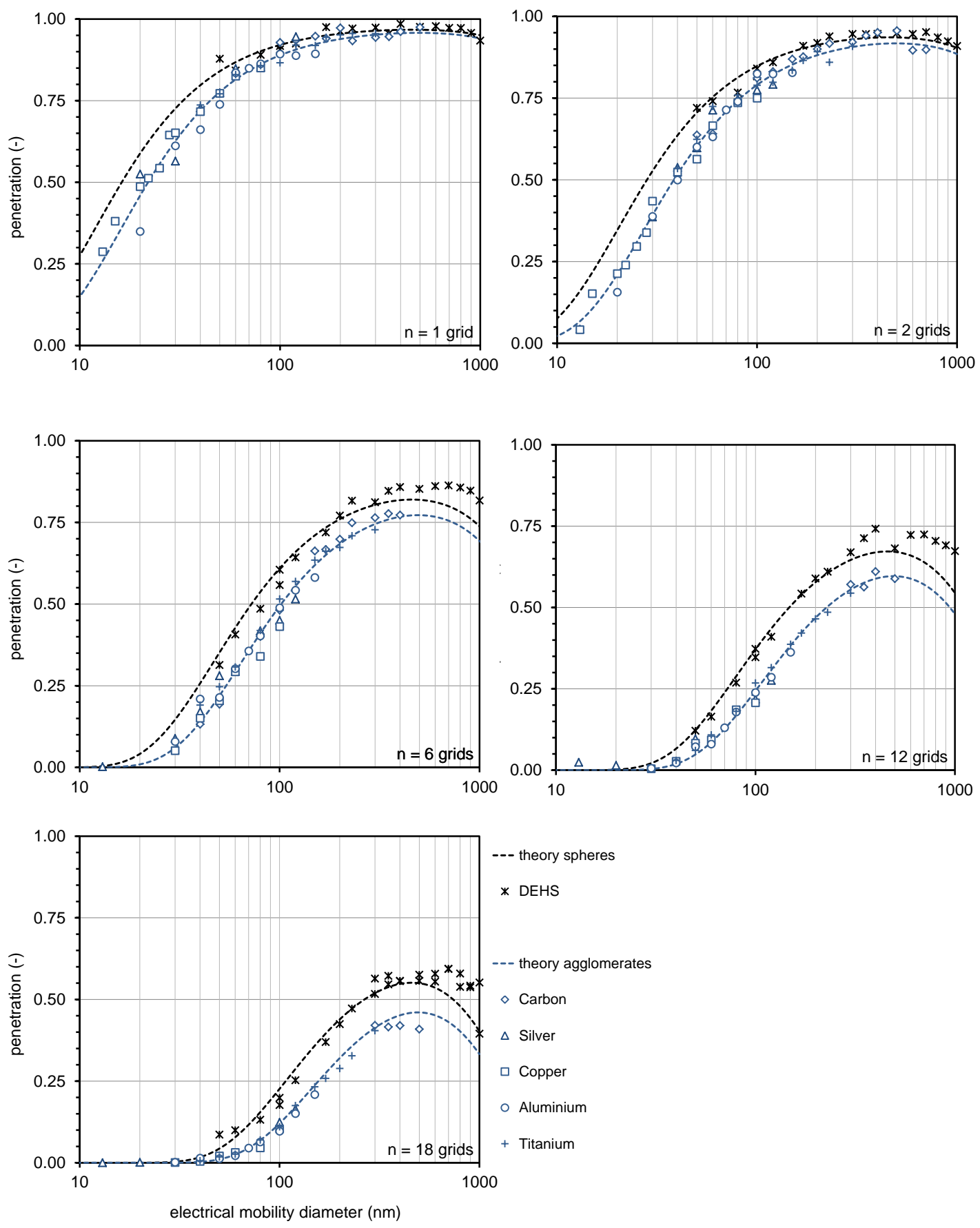

Figure 4. Experimental and theoretical particle penetration through $n$ diffusion grids. 

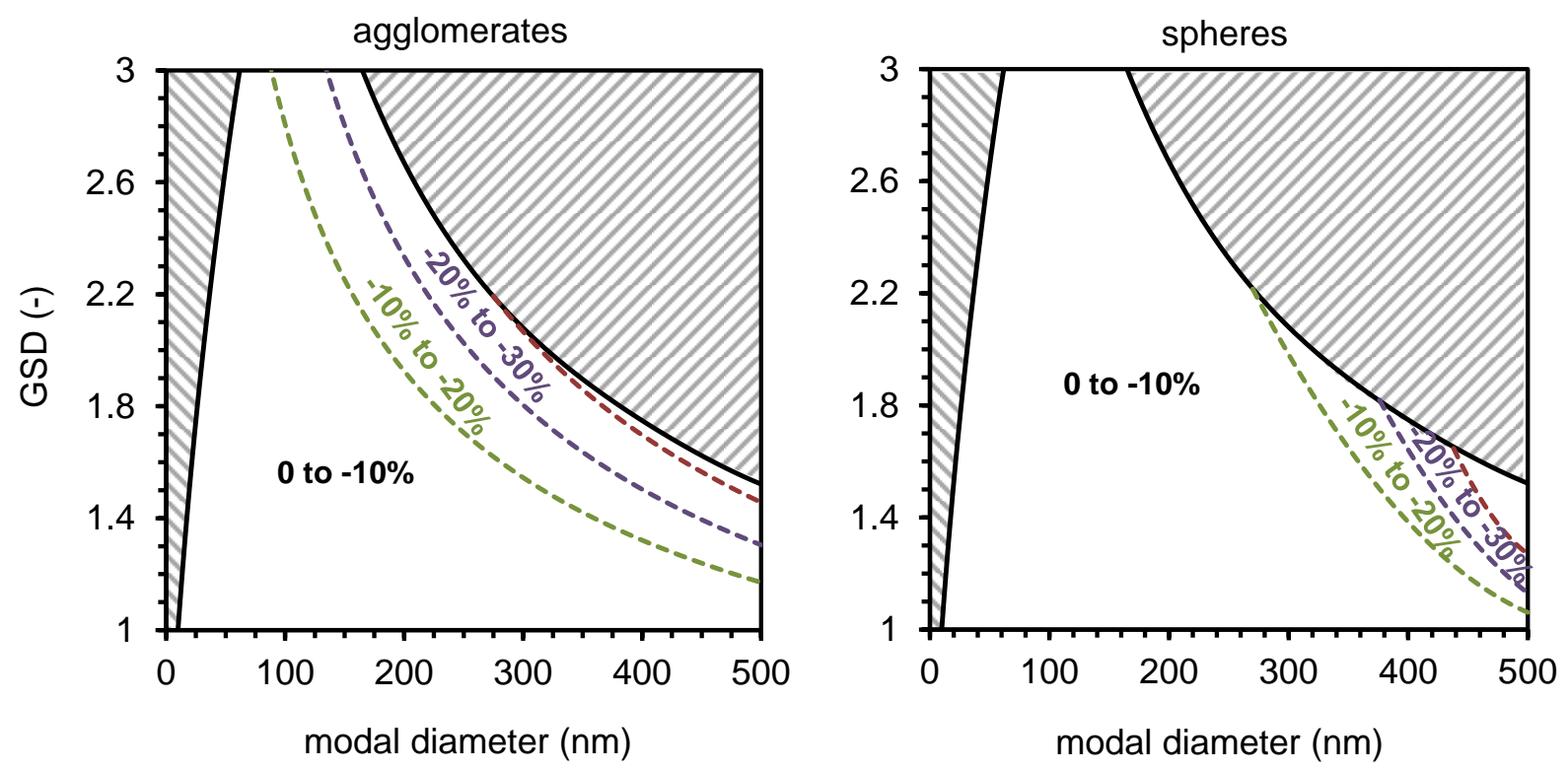

Figure 5. Bias maps of the modal diameter stemming from PSS-CPC approach with regards to the reference (input) modal diameter for agglomerates and spheres. The green, purple and red curves correspond to a discrepancy in terms of modal diameters of $-10 \%,-20 \%$ and $-30 \%$, respectively. The area on the left of the green curve represents situations with biases ranging from 0 to $-10 \%$. Reciprocally, the area on the right of the red curve corresponds to conditions leading the biases below $-40 \%$. 

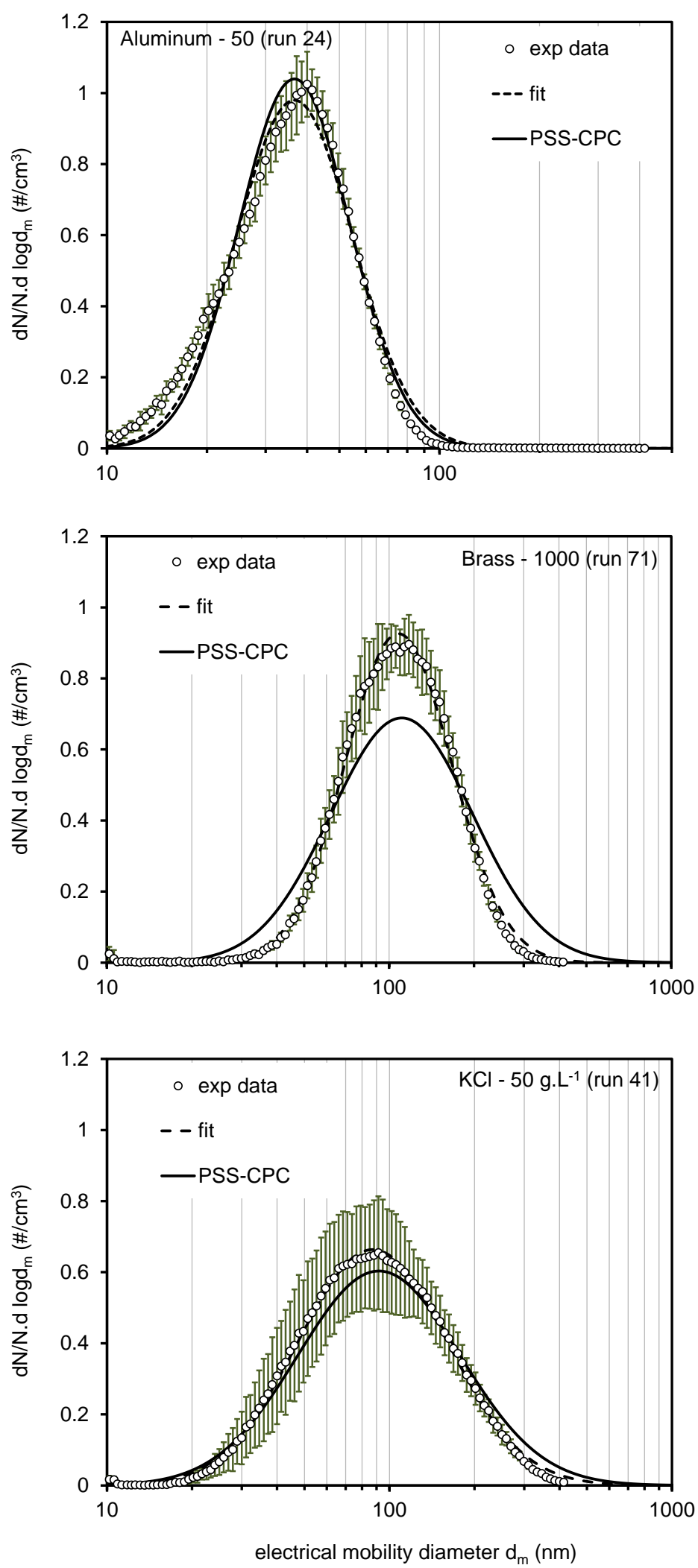

Figure 6. Three examples of output of the PSS-CPC approach compared to experimental and fitted SMPS data. 


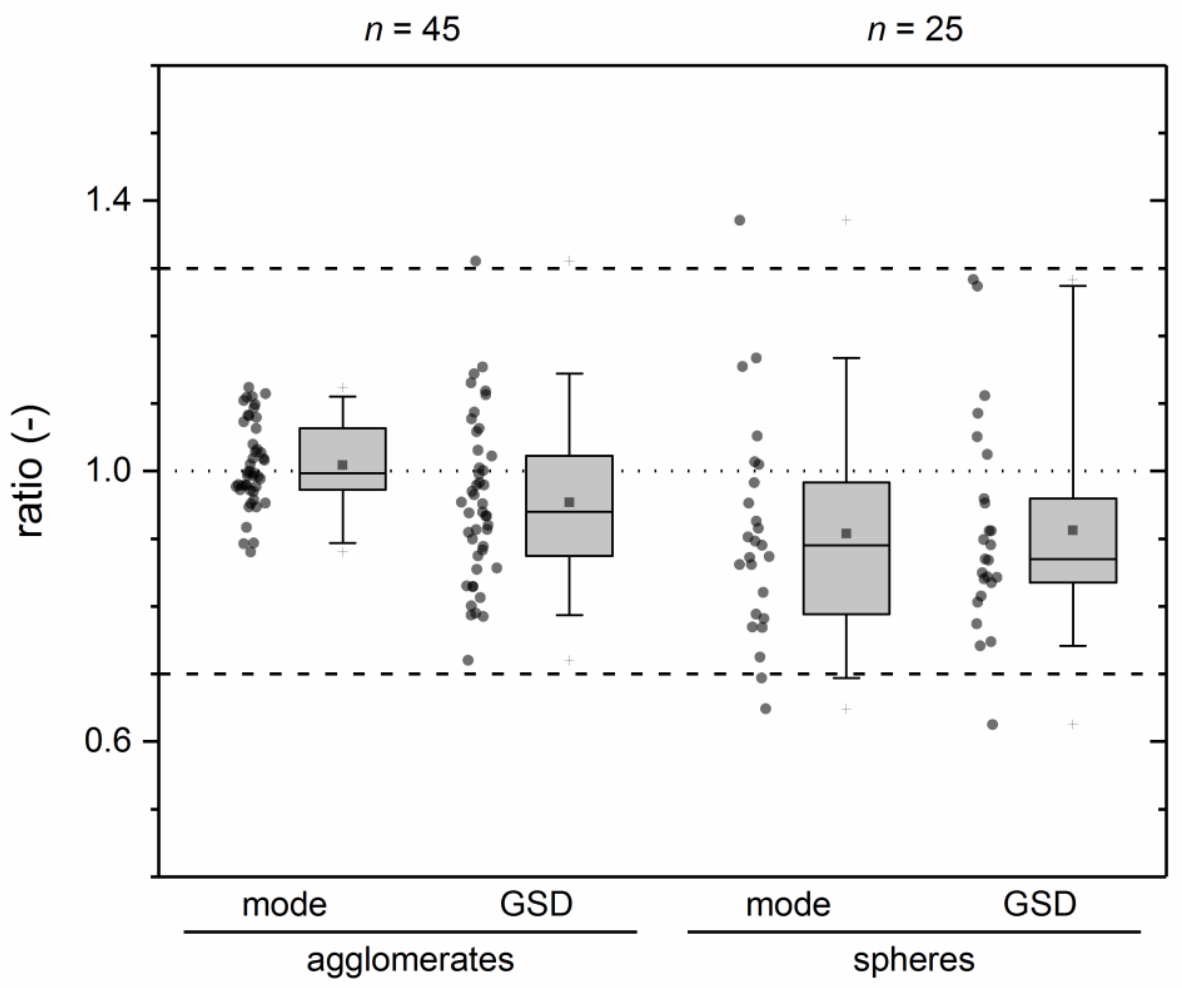

Figure 7. Boxplots of the ratio between PSS-CPC-based and SMPS-based parameters (mode, GSD) observed for the different test aerosols. 

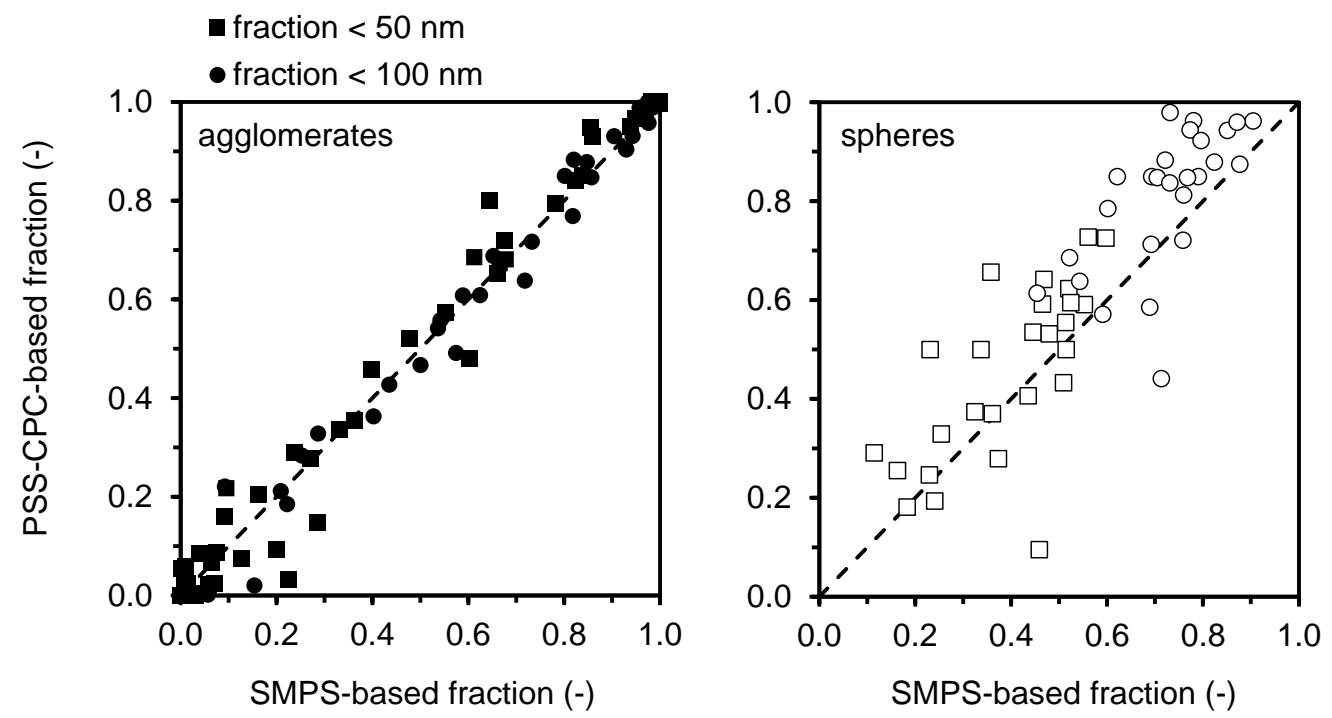

Figure 8. Fractions of particles (below $50 \mathrm{~nm}$, below $100 \mathrm{~nm}$ ) calculated from the PSSCPC approach and compared to SMPS-fitted data. 


\section{Tables}

Table 1. Equations used for the calculation of particle penetration through diffusion grids.

\begin{tabular}{|l|l|l|l|l|}
\hline & Collection efficiency & Additional parameters & Comments & References \\
\hline
\end{tabular}




\begin{tabular}{|c|c|c|c|c|}
\hline 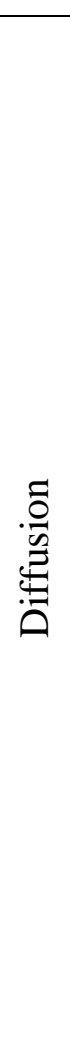 & $E_{D}=B P e^{-\frac{2}{3}}$ & $\begin{array}{c}P e=\frac{U_{0} d_{f}}{D} \\
D=\frac{k_{B} T C u\left(d_{p}\right)}{3 \pi \eta_{g} d_{p}}\end{array}$ & $\begin{array}{l}B \in[1.5 ; 2] \text { for real filter } \\
P e: \text { Peclet number (-) } \\
D: \text { diffusion coefficient } \\
\left(\mathrm{m}^{2} / \mathrm{s}\right) \\
U_{0}: \text { velocity (m/s) } \\
d_{f}: \text { fibre diameter (m) } \\
k_{B}: \text { Boltzmann's constant } \\
T: \text { temperature (K) } \\
C u: \text { Cunningham's slip } \\
\text { correction factor (-) } \\
\eta_{g}: \text { gas viscosity (Pa.s) }\end{array}$ & $\begin{array}{l}\text { Cheng and Yeh } \\
\text { (1980); Stechkina and } \\
\text { Fuchs (1966) }\end{array}$ \\
\hline
\end{tabular}




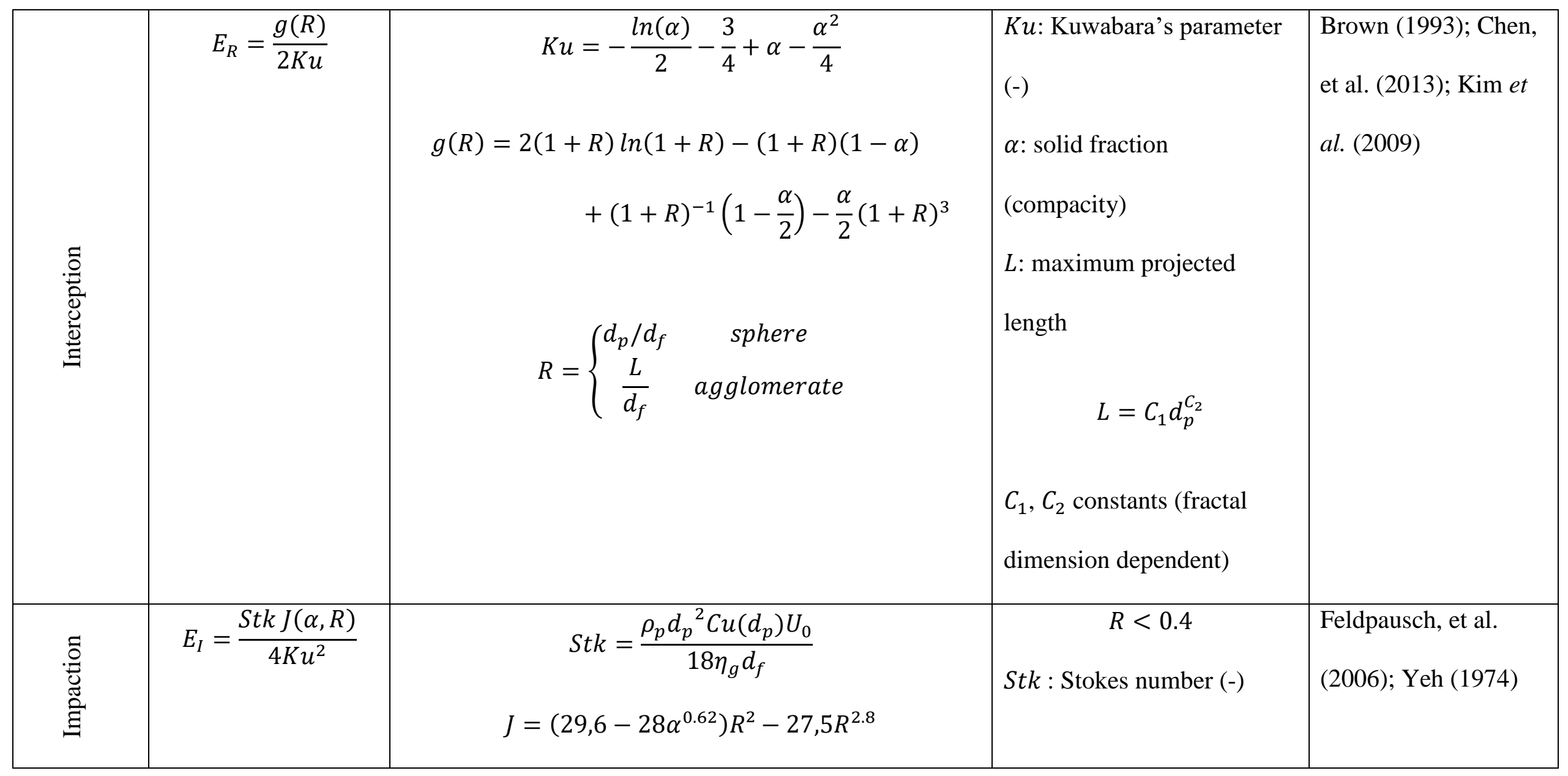




\begin{tabular}{|c|c|c|c|}
\hline 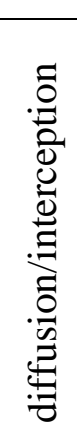 & $E_{D R}=\frac{1.24 R^{\frac{2}{3}}}{(K u \cdot P e)^{\frac{1}{2}}}$ & & Hinds (1999) \\
\hline 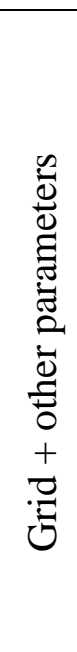 & $U_{0}=\frac{4 Q_{\text {aero }}}{\pi d_{e f f}^{2}}$ & $\begin{array}{l}Q_{\text {aero }}=0.7 \mathrm{~L} \cdot \mathrm{min}^{-1} \\
d_{e f f}=45.5 \mathrm{~mm} \\
\alpha=0.37 \\
\text { Fibre diameter } \mathrm{d}_{\mathrm{f}}=20 \mu \mathrm{m} \\
\text { Thickness } \mathrm{t}=42 \mu \mathrm{m} \\
\text { Aperture size } \mathrm{w}=20 \mu \mathrm{m} \\
\text { material: } 1.4401 / \text { AISI } 316 \text { stainless steel }\end{array}$ & $\begin{array}{l}\text { Feldpausch, et al. } \\
\text { (2006) }\end{array}$ \\
\hline
\end{tabular}


Table 2.Test aerosols for penetration measurement.

\begin{tabular}{|l|l|l|l|}
\hline Particle & Generation setup & Substance & $\begin{array}{l}\text { Range of mobility } \\
\text { diameter (nm) }\end{array}$ \\
\hline Agglomerates & CAIMAN (Jacoby, et al., & $\mathrm{C}$ & $100-500$ \\
\cline { 3 - 4 } & 2011) & $\mathrm{Ag}$ & $13-120$ \\
\cline { 3 - 4 } & & $\mathrm{Cu}$ & $13-100$ \\
\cline { 3 - 4 } & & $\mathrm{Al}$ & $20-150$ \\
\cline { 3 - 4 } & & Ti & $40-300$ \\
\hline Spheres & Nebulizer (Palas AGK2000) & DEHS & $50-1000$ \\
\hline
\end{tabular}


Table 3.Test aerosols for number size distribution measurement.

\begin{tabular}{|c|c|c|c|c|c|c|}
\hline $\begin{array}{c}\text { Particle } \\
\text { morphology }\end{array}$ & $\begin{array}{l}\text { Generation } \\
\text { setup }\end{array}$ & Substance & $\begin{array}{l}\text { Range of } \\
\text { Modal } \\
\text { diameter } \\
(\mathrm{nm})\end{array}$ & $\begin{array}{l}\text { Range of } \\
\text { GSD (-) }\end{array}$ & $\begin{array}{c}\text { Range of } \\
\text { Number } \\
\text { concentration } \\
\mathrm{C}_{\mathrm{N}}\left(10^{3} \# / \mathrm{cm}^{3}\right)\end{array}$ & $\begin{array}{l}\text { Number of } \\
\text { experiments } \\
n\end{array}$ \\
\hline \multirow{7}{*}{ 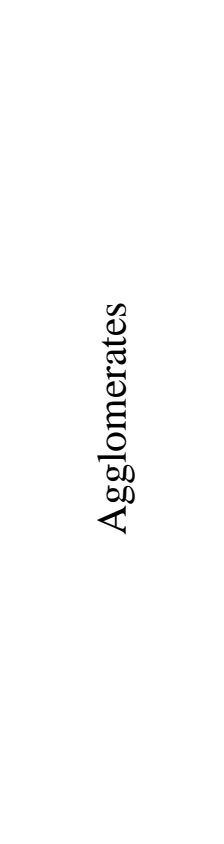 } & \multirow{7}{*}{$\begin{array}{c}\text { CAIMAN } \\
\text { (Jacoby, et al., } \\
\text { 2011) }\end{array}$} & $\mathrm{C}$ & $41-270$ & $1.46-1.58$ & $43-93$ & 8 \\
\hline & & $\mathrm{Cu}$ & $16-70$ & $1.45-1.56$ & $17-77$ & 7 \\
\hline & & $\mathrm{Al}$ & $25-96$ & $1.50-1.53$ & $38-71$ & 7 \\
\hline & & $\mathrm{Ti}$ & $42-159$ & $1.48-1.61$ & $29-53$ & 7 \\
\hline & & $\mathrm{Ag}$ & $9-71$ & $1.20-1.55$ & $16-89$ & 7 \\
\hline & & $\begin{array}{l}\text { Constantane } \\
\text { (Cu/Ni alloy) }\end{array}$ & $31-139$ & $1.50-1.54$ & $37-94$ & 7 \\
\hline & & $\begin{array}{c}\text { Brass }(\mathrm{Cu} / \mathrm{Zn} \\
\text { alloy) }\end{array}$ & $20-107$ & $1.50-1.55$ & $35-82$ & 7 \\
\hline \multirow{9}{*}{$\begin{array}{l}\frac{n}{0} \\
\frac{0}{2} \\
\text { के }\end{array}$} & \multirow{3}{*}{$\begin{array}{c}\text { Atomizer (TSI } \\
\text { 3076) }\end{array}$} & $\mathrm{NaCl}$ & $62-97$ & $1.87-1.95$ & $57-94$ & 3 \\
\hline & & $\mathrm{KCl}$ & $62-108$ & $1.84-1.89$ & $57-93$ & 3 \\
\hline & & $\mathrm{CsCl}$ & $54-92$ & $1.72-1.78$ & $34-70$ & 3 \\
\hline & \multirow{3}{*}{$\begin{array}{l}\text { Home-Made } \\
\text { Laskin-type } \\
\text { nebulizer }\end{array}$} & $\mathrm{NaCl}$ & $47-54$ & $2.96-3.57$ & $12-59$ & 3 \\
\hline & & $\mathrm{KCl}$ & $36-50$ & $2.95-3.33$ & $13-62$ & 3 \\
\hline & & $\mathrm{CsCl}$ & $41-45$ & $2.53-3.03$ & $11-31$ & 3 \\
\hline & \multirow{3}{*}{$\begin{array}{l}\text { Nebulizer } \\
\text { (PALAS } \\
\text { AGK 2000) }\end{array}$} & $\mathrm{NaCl}$ & $48-90$ & $2.0-2.48$ & $28-88$ & 3 \\
\hline & & $\mathrm{KCl}$ & $45-83$ & $1.97-2.1$ & $42-57$ & 3 \\
\hline & & $\mathrm{CsCl}$ & $42-68$ & $1.92-2.01$ & $23-51$ & 3 \\
\hline
\end{tabular}

